\title{
Flexible and Friendly, But it is fair? Work - life considerations needs delicate balance
}

\author{
Rajeesh Viswanathan, N. Sarath Lal, Veena Prasad, Jahira Parveen
}

\begin{abstract}
For a business to thrive in the current globalization phase, it has to get the formost from its workforce. To do this, staffs got to feel their firms are in obtaining their needs consummated. Its vital to identify and respect the individual requirements of workers. Now it's not simply a matter of payment and personal promotional prospects. Employees are increasingly basing employment verdict on how well their current potential workplace can support a balance between personal lives and paid occupation. As a result, the employers have changed the operational style and made the work place more friendly and flexible. The paper aims at looking in to the factors that constitute work life balance and also analyze the effect of demographic variables on work life balance. The study was done on the employees of Software and BPO industry. A sample of 315 employees from 10 Software and 10 BPO companies from in and around Madras and Pondicherry was studied. Employee turns out to be a productive provided the environment is conducive. It counts on various factors like supervisor subordinate relations as well as the peer relations. Today IT sectors take up the contract with extremely low quotes which would be enough to just meet the operating expenses. In such a scenario management puts the work pressure on the employee which is beyond the capacity of the employee and time frame.
\end{abstract}

Index Terms: Organisational Culture, Work life balance, Commitment, Employee engagement.

\section{INTRODUCTION}

Working environment today has changed compared to last two decades. The challenges of business have been growing since the players have been increasing. The demands for increasing the competence and becoming further responsive to the consumers, clients and stakeholders have become the main agenda. Mean while the internal stress abound from employee who is placing even more pressures on employers by seeking rewarding employment that allows for skills utilization, rewarding careers and life outside the office. The working environment has taken a new face. It's no longer just a matter of payment and personal promotional prospects. Employees are increasingly basing employment verdict on how well their current potential workplace can support a balance between personal lives and paid occupation. As a result, the employers have changed the operational style and made the work place more friendly and flexible. Absence of applying such methods faces high level of absenteeism and

Revised Manuscript Received on July 05, 2019

Dr. Rajeesh Viswanathan, Asst Prof,Dept of International Business, School of Management, Pondicherry University, Pondicherry.

N. Sarath Lal, Dept of International Business, School of Management, Pondicherry University, Pondicherry.

Dr Veena Prasad, Prof, Shir Ram college of Commerce, Mumbai

Dr. Jahira Parveen, Faculty of Management, SRM Institute of Technology, Chennai. attrition rate. It leads to brain drain and are trailing highly experienced professionals to other flexible organizations.

For a business to succeed, it must get the foremost from its force. To do this, workers ought to feel their organization in obtaining their wishes consummated. It's essential to acknowledge and honor the individual requirements of employees. In other words, adjust working patterns for everyone, regardless of caring responsibilities, age rate race gender or disability, so that they can find a rhythm that enables them to more easily combine work with other res ponsibilities and aspirations.

Smarter work can be in different types, from flexibility of working hours like compressed weeks, to availability of hours, like tele / remote working space. Levels of implementation vary from nippy wins such as flexibility around initiate and finish period, which have less cost implication, through to full organizations workflow review that embrace change management and workforce planning. A management with established work-life-balance initiatives can root to relieve stress in employees, and this would promote the business by creating more focused as well as committed teams, dropping down the absenteeism and improving productivity.

\section{REVIEW OF LITERATURE}

The problems related to work-life balance is summed up in Hobson et al.'s (2001, p. 38) proposition that "personal and work-related problems invariably arise when individuals fail to effectively fullfil fundamental life or family responsibilities". The study of WLB initially emerged in the 1970 s, as a "women's issue", then, in the late 1980s, studies of work-life balance began to focus more on the development of effective recruitment/retention policies (Frame and Hartog, 2003). While early research considered individual psychology and motivation (Greenhaus and Beutell, 1985), for the most part the studies of the late 1980s through to the end of the 1990s focused more on policy development.

Dan Wheatley, (2012) reflect on the core divergence related with the existing work-life balance and travel-to-work policies, as engaged in organizations. The evidence presented in this work recommended: work-group cultures avert workers, specially women, from attaining work life balance; there is spill-over among work and non-work behavior, facing time allocation problems, and stress, for dual livelihood family circle effort to achieve desired work-life balance; and specific conflicts are reported in balancing work with travel-to-work.

Vathsala (2010) investigate occupational base stances of information technology (IT) facilitated business process outsourcing (ITES-BPO) employees. The conclusion advocates that occupancy has a important effect on chore

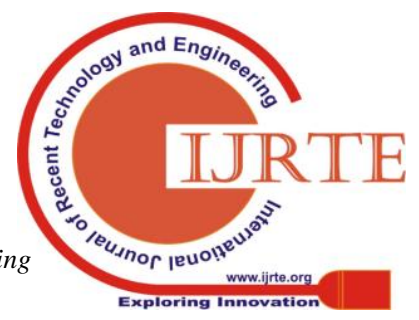


autonomy and marital status has a important consequence on operational hours.

Further new researches conducted in work-life balance have paying attention on the concept of "flexible firms" (Frame and Hartog, 2003), these are mainly concentrated on two related concerns. The first refers to the organizations which uses tele-communications and setting up to allow human resources to work at time and in place which are most fitting for each of the employees (Hobson et al., 2001). The other refers to organizations which expand and trim down workforces as required, in the course of using contract and transitory lab our (Frame and Hartog, 2003). The prospects of being capable of work at any moment of time and at any place has been seen as aperture the way up to being capable to change one's plan to fit in all of one's dedications. Hobson et al. (2001) propose that in disparity of Frame and Hartog (2003, p. 359) disparage the new "flexible" hiring of a transitory labor force quoting Lewis and Dyer (2002, p. 304) as saying "family tilting strategies are do not often apply to this subject and marginal workforce". on the other hand, a closer contemplation put forward that this condition may not essentially be the case: Stopper et al. (2003), for instance, involve that the piece of information that it is now potential to work 24/7 means that there is more stress for workers to do so. Therefore it is not understandable which characteristics of the new flexibility of firms are a encouraging, and which is having a negative influence on expansion for the conservation of work-life balance.

Pervasiveness of technology has led to breaking of boundaries of the organizational timings. IT companies having its client offshore and employees working in team with the project members are compelled to work as per the client timings which could be late hours at the parent company site. This in turn affects the work life balance and disturbs the family. Hence, organization should come out with strict regulations where by such issues could be posted on mail and if there exist a real need or review it could be carried out weekly once. This would facilitate and make the employees more active and committed towards the organization. (Peters, A., Dray, S., Kaye, J.,) Work-family imbalance not only leads to intrapersonal role conflicts but also typically involves and leads to interpersonal conflicts. As its said conflict is inevitable in any place, but there are three ways to solve the conflict - domination, compromise, integration, avoidance and accommodation. If integration or in certain cases accommodation is possible provided the organization has clear working polices in the case of working from home. But if working from home turn out to be negative it paves way for interpersonal conflict. Further, if the policies are not clear it leads to intrapersonal conflict. Hence, organization should design the policies in such a manner that it does not affect the employees work life balance. If not identified this in turn badly effects the efficiency of the employees and in turn the productivity of the organization. (Lu, J., Tjosvold, D., Shi, K., Wang, B.)

It was observed that in spite of growing body of literature on investigating work life balance, scholar have inferred that intellectual follow a line of investigation lags at the back of researchers advance (Macey and Schneider, 2008). despite the fact that there has been preliminary studies on the association of leadership proportions with engagement, this prose is restricted in that and measures of engagement have not been make available for inquiry
Susana studied the awareness of institutional stress on employers to get better the work-life balance in demanding background with complex monetary and economic state of affairs and to organize organizations according to these conditions. The analysis clearly demonstrate the subsistence of three diverse groups of organizations according to their observation of coercive, mimetic and normative pressures, and the uniqueness of the group. The awareness of institutional forces decide the posture of the organization with regard to work-life balance

In certain situation it was found that women interpreted work in a different way and this led to conflict in the organization. This happened due to absence of clarity of the policies and proper communication. Hence, this can be removed if the clauses are communicated during the orientation programmes. Which would make the employee comfortable with the system. This in turn would lead the commitment and productivity. This would facilitate the employee in planning and making the decisions to balance the work and life (Favero, L.W., Heath, R.G.). If an organization tries to address the women issues, it would enable them to have a clear vision and take up challenging career. This would make them more specific in decision making with regard to personal and professional goals. They would be able to create a proper balance between the two without leading to any ambiguous scenario. Hence, organization should lay out the career growth and career plans in explicit way. Absence of this leads to many employees in a confusing situation and leads to build up stress in last minute.( Kawase, K. , Kwong, A.)

In totting up, the extant of research on work-life balance point out that the blow of flexible working, and of family-friendly policy, on work-life balance is not evidently implicit, and that disparity at diverse levels of the organization are noted but not empirically investigated: it is merely implicit that there is a optimistic relationship among good work-life balance awareness and loyalty to the organizations.

Jessica (2011) states that three aspects come out from the JRA 360: supports team, performs efficiently, and demonstrate integrity. Correlation and regression outcome explains that team supports is the important determinant of engagement; semi-partial correlations envisage that the three leadership dimensions overlie in their associations with engagement, with supports team foretell the majority sole discrepancy within an institution undergo the cultural transformation, while taking the issues of examine and rising levels of staff engagement over time. It follows a company through enormous organizational change, firstly towards a high performance culture and then to a culture of empowerment The role of engagement and monitoring processes are highlighted as part of the transition.

Mohd Yasin (2013) analysis using structural equation modeling reveals that the transformational leadership style influences followers' attributes of work life balance. The direct relationship between transformational leadership and work life balance was found to be partially mediated by employees' perceptions of meaning in work.

Deirdre Anderson (2009) studies show that flexible working has an impact on employee engagement through a positive relationship with organizational commitment, 
job satisfaction and employee discretionary behavior. Allowing employees a degree of choice over when, where and how much work they do has benefits for the organization. However, for these gains to be realized, support is needed for the implementation of a flexible working policy.

Though so many studies have been done to identify the factors leading to work life balance, still the IT sectors continue to face this problem. Even though they pay good take home salary, still the level of commitment and engagement towards the organization remains to be minimal. Current study intends to find out how organization could enhance the level of work life balance among the employees of IT sectors. It was observed that the factors like decision making, conducive working climate, nurturing environment and its impact on work life balance was not studied. The present study intends to identify the missing link between these factors.

\section{RESEARCH METHODOLOGY}

The paper aims at looking in to the factors that constitute work life balance and also analyze the effect of demographic variables on work life balance. The study was done on the employees of Software and BPO industry. A sample of 315 employees from 10 Software and 10 BPO companies from in and around Madras and Pondicherry was studied. The sampling procedure was non probability convenience. The instrument used for data collections was a questionnaire which had two parts, first part was to measure work life balance and the second part was on personal profile. A five point Likerts scale was constructed to measure work life balance and the scale was tested for validity and reliability with data from pilot study which was done on a sample of 50 employees from Madras. Face validity was attempted for which a panel of 5 experts was identified from Industry (HR), Education (Professor) and Psychologist (Practitioner) and all the five were satisfied with the construct and the reliability was measured using cronbach's alpha and the value was found to be 0.903 . The components were reduced to manageable items and analysis was applied to see which factor or item plays a very important role in identifying the work life balance in an organization. To find the quality of work life for the IT professionals we have used One way ANOVA where we are finding the relationship between Quality of work life and decision making, communication and enhancing their skills and knowledge respectively.

Objetives:

- To analyze the prevailing work life balance strategies followed in IT sectors.

- To analyse whether the prevailing WLB enhance my skills and updating my knowledge.

- Recognition of ideas and suggestion put upon.

RELIABILITY:

Reliability Statistics

\begin{tabular}{|l|l|}
\hline $\begin{array}{l}\text { Cronbach's } \\
\text { Alpha }\end{array}$ & N of Items \\
\hline .931 & 34 \\
\hline
\end{tabular}

ONE WAY ANOVA:

Difference between Task variety, Task autonomy and work life balance.

\begin{tabular}{|c|c|c|c|c|c|c|}
\hline \multicolumn{7}{|c|}{ ANOVA } \\
\hline & & Sum of Squares & $\mathrm{df}$ & Mean Square & $\bar{F}$ & Sig. \\
\hline \multirow{4}{*}{ TA } & Between Groups & 5456387 & 14 & 389.742 & 527.793 & .000 \\
\hline & Within Groups & 118.150 & 160 & .738 & & \\
\hline & Toxa1 & 5574.537 & 174 & & & \\
\hline & Between Groups & 2190.137 & 14 & 156.438 & 10429.224 & .000 \\
\hline \multirow[t]{2}{*}{ TV } & Within Groups & 2.400 & 160 & .015 & & \\
\hline & Toxal & 2192.537 & 174 & & & \\
\hline
\end{tabular}

There is significance between the variables. So, reject H0.

$\mathrm{H} 0$ : There is no significance difference between task variety, task autonomy and work life balance.

H1: There is significance difference between task variety, task autonomy and work life balance.

CORRELATION:

Relationship task autonomy and work life balance.

\begin{tabular}{|l|l|r|r|}
\hline \multicolumn{4}{|c|}{ Correlations } \\
\hline \multirow{4}{*}{ WLB } & Pearson Correlation & \multicolumn{1}{c|}{ WLB } & \multicolumn{1}{c|}{ TA } \\
\cline { 2 - 4 } & Sig. (2-tailed) & 1 & $.923^{* *}$ \\
\cline { 2 - 4 } & $\mathrm{N}$ & 175 & .000 \\
\hline \multirow{4}{*}{ TA } & Pearson Correlation & $.923^{* *}$ & 175 \\
\cline { 2 - 4 } & Sig. (2-tailed) & .000 & 1 \\
\cline { 2 - 4 } & N & 175 & 175 \\
\hline
\end{tabular}

**. Correlation is significant at the 0.01 level (2-tailed).

There is significance between the variables. So, reject $\mathrm{H} 0$.

H0: There is no relationship task autonomy and work life balance.

H1: There is relationship task autonomy and work life balance.

Relationship task variety and work life balance:

\begin{tabular}{|l|l|r|r|}
\hline \multicolumn{4}{|c|}{ Correlations } \\
\hline \multirow{4}{*}{ WLB } & Pearson Correlation & \multicolumn{1}{|c|}{ WLB } & \multicolumn{1}{c|}{ TV } \\
\cline { 2 - 4 } & Sig. (2-tailed) & 1 & $.996^{* *}$ \\
\cline { 2 - 4 } & $\mathrm{N}$ & 175 & .000 \\
\hline \multirow{4}{*}{ TV } & Pearson Correlation & $.996^{* *}$ & 175 \\
\cline { 2 - 4 } & Sig. (2-tailed) & .000 & 1 \\
\cline { 2 - 4 } & N & 175 & 175 \\
\hline \multirow{2}{*}{$* *$ Correlation is significant at the 0.01 level (2-tailed). } \\
\hline
\end{tabular}

There is significance between the variables. So, reject $\mathrm{H} 0$. $\mathrm{H} 0$ : There is no relationship task variety and work life balance.

H1: There is relationship task variety and work life balance.

\begin{tabular}{|c|c|c|c|c|c|c|}
\hline \multicolumn{7}{|c|}{$\begin{array}{l}\text { REGRESSION: } \\
\text { Coefficients }\end{array}$} \\
\hline \multirow{2}{*}{\multicolumn{2}{|c|}{ Made1 }} & \multicolumn{2}{|c|}{ Unstandardized Coefficients } & \multirow{2}{*}{$\begin{array}{l}\text { Standardized } \\
\text { Coefficients } \\
\text { Beta }\end{array}$} & \multirow[t]{2}{*}{$\mathrm{t}$} & \multirow[t]{2}{*}{ Sig. } \\
\hline & & B & Std. Error & & & \\
\hline \multirow{3}{*}{1} & (Constani) & .740 & .262 & & 2.822 & .005 \\
\hline & TA & .214 & .015 & .142 & 14.035 & .000 \\
\hline & TV & 2.078 & .024 & .868 & 85.665 & .000 \\
\hline
\end{tabular}

There is significance between the variables. So, reject H0.

H0: There is no relationship task variety, task autonomy and work life balance.

H1: There is relationship task variety, task autonomy and work life balance.

\section{DISCUSSION}

From the analysis we have found that there is a significance relationship

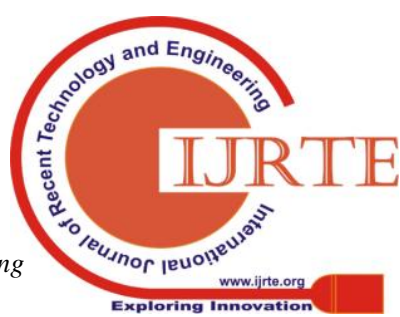


between work life balance and productivity. So there is a positive relationship between work life balance and productivity. There is a positive relationship between quality of work life and enhancing their skills and updating their knowledge and when they are able to enhance their knowledge and skills their quality of work has been influenced. There is a relationship between quality of work and communication where when the communication is lagging the quality of work is affected.

With the advent of technology and sophistication organizations though they preach work life balance, but in reality its not much evident, like a scenario when an employee is compelled to work again even after reaching home especially in IT sectors, who's would be having project offshore working in different times. His mindset would be tuned to the office environment. Hence, the purpose of early leaving or spending time with family is not feasible. In such scenario it widens the relationship of the employee with the organization.

Organization should try to design the work schedules and operating style in such a way that no employee works on office job after office hours. This is possible if we set the schedule and have close monitoring. Provided we are able to work on the profile exactly.

Employee turns out to be a productive provided the environment is conducive. It counts on various factors like supervisor subordinate relations as well as the peer relations. Today IT sectors take up the contract with extremely low quotes which would be enough to just meet the operating expenses. In such a scenario management puts the work pressure on the employee which is beyond the capacity of the employee and time frame. A work that which is to be completed by three person will be made to handle by single person. In such a scenario, his loading gets high and secondly the time constraints makes him lead to a stressful situation. As it's a chain every person starts putting pressure down line. This forces the employee to work extra hours and finally not able to balance the work and family. Even though in certain cases once employee reaches home, but he again resumes the office work. Hence, IT sectors can reduce the salary and increase the number of employees, whereby work life balance can be maintained in the sector.

An individual leaves for his family and prefers to be with his family for a major time. Its observed that most prefer to carry the work home, one of the reason is that at least they are able to reach home and attend to the loved ones and also able to do the work. This strategy sounds good in the initial stage. But as the time goes family gets vexed, as half the time even though their spouse is at home, but its only physical not mentally. Hence, its appreciated that even if work is carried home, we should ensure that organization should create time restrictions for it. They should not allow to cross the limits ie., stop the connectivity or block the operations after the fixed time, where by even if employee wants to cant access the system.

Its felt that employees don't get the desired help as expected. Emotional support comes with the value system of the organization.

\section{CONCLUSION}

Employees should be recognized for the task done by them and same time involved in decision making. Where by they get a feeling that they are part and parcel of the organization. Even though many organization do practice work life balance like flexi timing and working from home, at time mainly in the IT sectors, most of the projects are done off shore and employees are compelled to answer the query posed at the client site which generally takes place after the domestic working hours. So in reality there is a absence of work life balance. Organization should stress on for what's being followed in true spirit. This would enhance the level of commitment and create an ideal work life balance among the employees.

\section{Limitations}

- This study pertains to Chennai and Bangalore only and it may differ in other parts of the World.

- Ten IT \& ITES companies has been taken and some more companies can also be included.

\section{Future Research}

Future researcher can include more variables and can also use more tools and the data can be collected through different methods and the samples can also be increased. The data can be collected from different levels of employees like top management, middle management and can also be increased with organizational engagement, team engagement and job engagement.

\section{REFERENCES}

1. A Peters, H Winschiers-Theophilus, B Mennecke, Cultural influences on Facebook practices: A comparative study of college students in Namibia and the United States,Computers in Human Behavior 49 (August 2015), 259-271

2. Anderson, N. R., \& West, M. A. (1998). Measuring climate for work group innovation: development and validation of the team climate inventory. Journal of organizational behavior, 235-258.

3. Bain, P. G., Mann, L., \&Pirola-Merlo, A. (2001). The innovation imperative: The relationships between team climate, innovation, and performance in research and development teams. Small group research, 32(1), 55-73

4. Burningham, C., \& West, M. A. (1995). Individual, climate, and group interaction processes as predictors of work team innovation. Small group research, 26(1), 106-117.

5. Černe, M., Jaklič, M., \&Škerlavaj, M. (2013). Authentic leadership, creativity, and innovation: A multilevel perspective. Leadership, $9(1)$ 63-85.

6. Dackert, I., Lööv, L. Å., \&Mårtensson, M. (2004). Leadership and climate for innovation in teams. Economic and Industrial Democracy, 25(2), 301-318.

7. Dan Wheatley, (2012) "Work-life balance, travel-to-work, and the dual career household", Personnel Review, Vol. 41 Iss: 6, pp.813 - 83

8. Dan Wheatley, (2012) "Work-life balance, travel-to-work, and the dual career household", Personnel Review, Vol. 41 Issue: 6, pp.813-831

9. Frame, P., \& Hartog, M. (2003). From rhetoric to reality. Into the swamp of ethicallpractice: implementing work-life balance. Business Ethics: A European Review, 12(4): 358-367

10. Greenhaus, J. H., \& Beutell, N. J. (1985). Sources of Conflict between Work and Family Roles. Academy of Management Review, 10, 76-88.

11. Hobson, A.J., (2009), "On being bottom of the pecking order: beginner teachers' perceptions and experiences of support", Teacher Development: An international journal of teachers' professional development", Vol. 13 No. 4, pp. 299-320

12. Imran, R., Saeed, T., Anis-Ul-Haq, M., \& Fatima, A. (2010). Organizational climate as a predictor of innovative work behavior. African Journal of Business Management, 4(15), 3337. 
13. Leroy, H., Palanski, M. E., \& Simons, T. (2012). Authentic leadership and behavioral integrity as drivers of follower commitment and performance. Journal of Business Ethics, 107(3), 255-264.

14. Lewis,R.E. and Heckman, R.J. (2006) "Talent Management: A critical review",Human Resource Management Review, 16, 139-154.

15. Liu, F. C., Cheng, K. L., Chao, M., \& Tseng, H. M. (2012). Team innovation climate and knowledge sharing among healthcare managers: mediating effects of altruistic intentions. Chang Gung Med $J, 35(5)$, 408-419.

16. Mathisen, G. E., Einarsen, S., Jørstad, K., \&Brønnick, K. S. (2004). Climate for work group creativity and innovation: Norwegian validation of the team climate inventory (TCI). Scandinavian Journal of Psychology, 45(5), 383-392.

17. Pilař, L., Pokorná, J., \&Balcarová, T. (2014). Pro-active Behaviour in Context of Team Climate. Acta UniversitatisAgriculturae et SilviculturaeMendelianaeBrunensis, 62, 72.

18. Susana Pasamar, Ramón Valle Cabrera, (2013). "Work-life balance under challenging financial and economic conditions", International Journal of Manpower, Vol. 34 Iss: 8, pp.961 - 974

19. Vathsala Wickramasinghe, Saman Kumara, (2010). "Work-related attitudes of employees in the emerging ITES-BPO sector of Sri Lanka", Strategic Outsourcing: An International Journal, Vol. 3 Iss: 1, pp. $20-3$

20. Walumbwa, Fred O., Fred Luthans, James B. Avey, and Adegoke Oke. "Retracted: Authentically leading groups: The mediating role of collective psychological capital and trust." Journal of organizational behavior 32, no. 1 (2011): 4-24.

21. West, M. A., \&Altink, W. M. (1996). Innovation at work: Individual, group, organizational, and socio-historical perspectives. European Journal of Work and Organizational Psychology, 5(1), 3-11.

22. Yidong, T., \& Xinxin, L. (2013). How ethical leadership influence employees' innovative work behavior: A perspective of intrinsic motivation. Journal of Business Ethics, 116(2), 441-455. 